\title{
PENGARUH DANA KREDIT USAHA RAKYAT (KUR) TERHADAP BANK PERKREDITAN RAKYAT (BPR) DI KABUPATEN JEMBER
}

\author{
INFLUENCE OF BUSINESS RESPONSIBILITY CREDIT (KUR) ON RURAL BANK LOAN (BPR) \\ IN District of JEMBER \\ Nely Supeni \\ nely@stie-mandala.ac.id
}

Sekolah Tinggi Ilmu Ekonomi Mandala Jember

\begin{abstract}
ABSTRAK
Kredit Usaha Rakyat (KUR) adalah program pemerintah sebagai sumber dana untuk usaha Mikro, Usaha Kecil dan Menengah (UMKM) dengan suku bunga rendah, 9\% setiap tahun dan tanpa agunan. Tujuan penelitian ini adalah untuk mengetahui Debitur UMKM dan jumlah kredit debitur UMKM di BPR sebelum dan sesudah Program Tanggung Jawab KUR .. BPR di Kabupaten Jember adalah 23 BPR. Teknik pengambilan sampel adalah Jenuh Sampling (Sensus). Analisis data yang dilakukan adalah Paired Sample t Test dengan teknik menggunakan data melalui kuesioner. Hasil analisis adalah (1) Debitur UMKM di BPR sebelum dan sesudah program KUR sebesar 0,201 yang berarti lebih besar dari $\alpha=0,05$, sedangkan hasil keputusan yang diterima adalah Ho. Tidak ada pengaruh signifikan terhadap jumlah debitur UMKM di BPR sebelum dan sesudah program KUR, (2) Total Dana Kredit UMKM di BPR sebelum dan sesudah program KUR adalah 0,623 yang berarti lebih besar dari $\alpha=0,05$, Keputusan yang diambil adalah menerima Ho. Menerima Secara Jelas tidak ada perbedaan yang signifikan dengan jumlah dana kredit peminjam UMKM di BPR sebelum dan sesudah program pensiun KUR.
\end{abstract}

Kata kunci: KUR, UMKM, BPR

\section{ABSTRACT}

People's Business Credit (KUR) is a government program as a source of funds to Micro business, Small and Medium Enterprises (UMKM) with low interest rate, 9\% every year and without collateral. The purpose of this study is to find out the UMKM Debtor and the amount of credit of UMKM debtor at Rural Bank (BPR) before and after the KUR Responsibility Program. $B P R$ in Kabupaten Jember is 23 BPRs. Sampling technique is Saturated Sampling (Census). Data analysis conducted is Paired Sample $t$ Test with technique using data through questionnaire. The results of the analysis are (1) UMKM Debtor in BPR before and after KUR program equal to 0,201 which means bigger than $\alpha=0,05$, while result of decision received is Ho. There is no significant influence on the number of UMKM debtor in BPR before and after KUR program, (2) Total Credit Fund of UMKM in BPR before and after KUR program is 0,623 which means bigger than $\alpha=0,05$, The decision taken is receiving Ho. Receiving Hoibly there is no significant difference to the amount of credit funds of UMKM borrowers in BPR before and after the KUR pension program.

Keywords: People's Business Credit, Micro business, Small and Medium Enterprises, Rural Banks

\section{PENDAHULUAN}

Usaha Mikro, Kecil dan Menengah (UMKM) sepantasnya mendapatkan perhatian dan dukungan dari pemerintah, karena keberadaan UMKM sangat membantu perekonomian nasional dan membuka lapangan pekerjaan serta mengurangi pengangguran yang ada di Indonesia. Wujud dukungan pemerintah adalah dengan menyediakan sumber pembiayaan kredit melalui program pinjaman kredit bagi UMKM yang diberi nama Kredit Usaha Rakyat (KUR).

Kredit Usaha Rakyat (KUR) merupakan pinjaman kredit yang diluncurkan pemerintah dalam membantu Usaha Mikro, 
Kecil dan Menengah (UMKM) dalam mendapatkan tambahan dana untuk mengembangkan usahanya. Usaha Mikro, Kecil dan Menengah yang berhak mendapatkan bantuan KUR adalah UMKM yang memiliki usaha produktif dan layak mendapatkan bantuan. Usaha produktif yang dimaksudkan adalah usaha di bidang pertanian, perikanan dan kelautan, perindustrian, perdagangan, daan jasa-jasa (Lampiran I Peraturan Menteri Koordinator Bidang Perekonomian Selaku Ketua Komite Kebijakan Pembaiayaan Bagi Usaha Mikro, dan Menengah). Sedangkan yang dimaksud bahwa UMKM harus layak mendapatkan kredit adalah UMKM yang sehat, yang memiliki kemampuan mendapatkan keuntungan sehingga mampu mengembalikan pinjaman yang telah diberikan.

KUR terdiri dari 3 yaitu (1) KUR mikro yang besaran plafon masing-masing debitur maksimum Rp25.000.000,-, (2) KUR ritel yaitu kredit dengan plafon masing-masing debitur diatas Rp25.000.000,- dan maksimum Rp500.000.000,- dan (3) KUR TKI yaitu pinajaman KUR untuk membantu pembiayaan keberangkatan TKI (Tenaga Kerja Indonesia) ke negara penempatan dengan plafon maksimum sebesar Rp25.000.000,- .

Program pinjaman kredit tanpa agunan ini diberikan untuk pemberdayaan UMKM dengan bunga sebesar $9 \%$ per tahun per 1 januari 2016. Penyaluran kredit ini dilakukan melalui lembaga perbankan dan lembaga keuangan bukan bank yang telah di tunjuk dan di tetapkan oleh pemerintah karena layak sebagai pihak penyalur dana KUR. Diantaranya yaitu Bank Rakyat Indonesia (BRI), Bank Mandiri, Bank Bank Nasional Indonesia (BNI), Bank Pembangunan Daerah (BPD), Bank Umum Lain, LKNB (Lembaga Keuangan Non Bank). Dengan menggandeng beberapa bank tersebut, pemerintah berharap penyaluran KUR sesuai harapan, tepat sasaran dan bermanfaat bagi penguatan kelembagaan UMKM yang ada di Indonesia.

Program KUR dengan bunga ringan ini, tentunya akan berdampak bagi Perbankan dan Lembaga Keuangan Non Bank yang bukan penyalur dana KUR. Hal ini mengingat Perbankan dan Lembaga Keuangan Non Bank yang bukan penyalur dana KUR menyalurkan kredit kepada masyarakat dengan tingkat suku bunga tertentu, yang biasanya besaran tersebut jauh lebih tinggi dibandingkan suku bunga KUR. Contohnya Bank Perkreditan Rakyat. Bank Perkreditan Rakyat (BPR) sebagai lembaga perbankan yang menyalurkan kredit, memiliki kebijakan untuk menentukan berapa target kredit dan besaran bunga per tahun bagi debitur. Kebijakan ini di tetapkan masingmasing Bank Perkreditan Rakyat melalui program kerjanya yang dilaporkan kepada OJK (Otoritas Jasa Keuangan). Dari kebijakan menentukan besaran bunga tersebut, biasanya bunga BPR jauh lebih tinggi dibandingkan bunga KUR yang telah ditetapkan oleh pemerintah. Hal ini dikarenakan sebagian modal BPR di dapatkan dari modal pinjaman, sehingga BPR masih harus menanggung bunga pinjamannya, yang secara otomatis suku bunga bagi calon debitur akan lebih tinggi.

Bank Perkreditan Rakyat berharap mampu menjangkau seluruh lapisan masyarakat untuk mendapatkan kredit, baik debitur yang memiliki usaha atau tidak. Asalkan debitur dinilai mampu dan layak mendapatkan kredit melalui tahap analisis kredit BPR, maka pencairan kredit akan bisa dilakukan. Besaran kredit yang diterima debitur akan disesuaikan dengan kemampuan calon debitur tersebut.

BPR di Kabupaten Jember berjumlah 23 BPR. 20 diantaranya memang berasal dari BPR murni, sedangkan 3 yang lain berasal dari lembaga keuangan yang awalnya disebut KOP (koperasi) yang berkembang menjadi BPR. BPR-BPR di kabupaten Jember juga merasakan dampak adanya program KUR. Segmen pasar BPR yang begitu luas dari seluruh lapisan masyarakat sebelum ada KUR, kini tidak lagi sama. UMKM yang awalnya menjadi debitur BPR kini sebagian besar telah menjadi debitur KUR di beberapa bank. Adapun tujuan penelitian ini berdasarkan uraian diatas adalah: 1) untuk mengetahui berapa Jumlah Nasabah/Debitur UMKM pada Bank Perkreditan Rakyat (BPR) sebelum adanya program Kredit Usaha Rakyat (KUR), 2) untuk mengetahui berapa Jumlah Nasabah/Debitur pada Bank Perkreditan Rakyat (BPR) sesudah adanya program Kredit Usaha Rakyat (KUR), 3)untuk mengetahui berapapa jumlah Dana Kredit Debitur UMKM pada 
Bank Perkreditan Rakyat (BPR) sebelum adanya program Kredit Usaha Rakyat (KUR), dan 4) untuk mengetahui berapapa jumlah Dana Kredit Debitur UMKM pada Bank Perkreditan Rakyat (BPR) sesudah adanya program Kredit Usaha Rakyat (KUR)

\section{METODE PENELITIAN}

\section{Rancangan Dan Lokasi Penelitiann}

Rancangan penelitian yaitu Bagaimana program pemerintah sebagai sumber pembiayaan kredit bagi UMKM berpengaruh terhadap Bank Perkreditan Rakyat (BPR) di Kabupaten Jember. Indikator yang peneliti ambil adalah Jumlah Debitur dan Jumlah Dana Kredit pada Bank Perkreditan Rakyat sebelum dan sesudah adanya program KUR. Penelitian ini merupakan penelitian kuantitatif dengan menyebarkan kuesioner kepada sampel penelian. Adapun lokasi penelitian yaitu pada Bank Perkreditan Rakyat (BPR) yang ada di Kabupaten Jember.

\section{Jenis dan Sumber Data serta Metode Pengumpulan Data}

Jenis data dalam penelitian ini adalah data sekunder. Menurut Kuncoro (2003:127) Data Sekunder adalah salah satu jenis data berdasarkan sumbernya yang biasanya diperoleh dari sumber data. Data dalam penelitian ini juga termasuk data Rasio. Menurut Kuncoro (2003: 124) data rasio yaitu data yang diukur dengan suatu proporsi. Data rasio ini termasuk dalam statistik parametrik. Selanjutnya metode pengumpulan data yang peneliti lakukan adalah dengan menyebarkan kuesioner kepada para responden. Kuesioner yang disebarkan kepada responden berupa pertanyaan mengenai berapa jumlah debitur pada BPR sebelum dan sesudah adanya program KUR, dan berapa jumlah dana kredit pada BPR sebelum dan sesudah adanya program KUR.

\section{Populasi dan Sampel Penelitian}

Populasi dalam penelitian ini adalah seluruh Bank Perkreditan Rakyat (BPR) di Kabupaten Jember. Bank Perkreditan yang ada dikabupaten Jember sebanyak 23 BPR. Teknik Pengambilan Sampel yaitu dengan sampling jenuh. Menurut Sugiono (2013: 85) Sampling jenuh adalah teknik penentuan sampel bila semua anggota populasi digunakan sebagai sampel. Sampling jenuh (sensus) dipilih dikarenakan jumlah populasi yang relatif kecil dan biasanya dibawah 30 sampel.

\section{Analisis Data}

Berdasarkan data yang dimiliki dalam penelitian ini termasuk dalam statistik parametrik, sehingga analisis data yang digunakan adalah analisis Paired Sample t Test. Analisis Paired Sample $t$ Test merupakan analisis uji beda sampel berpasangan. Sampel berpasangan yang dimaksudkan adalah subjek penelitian yang sama namun mendapatkan perlakuan yang berbeda. Dari Teknik atau metode analisis data yang dilakukan tersebut, peneliti dapat mengorganisasikan data, kemudian melakukan uji Paired Sample t Test melalui SPSS, kemudian menginterpretasikan dan selanjutnya dapat diambil suatu kesimpulan.

\section{Uji Hipotesis}

Mengingat penelitian ini menggunakan uji Paired Sample t Test maka Hipotesis adalah sebagai berikut:

1. Menentukan tingkat signifikansi

Tingkat signifikasi yang di harapkan adalah $\alpha=5 \%$ atau confidence interval sebesar $95 \%$

2. Membandingkan nilai signifikansi dengan Tingkat signifikansi yang diharapkan dengan ketentuan sebagai berikut :

a. nilai signifikansi $<0,05$ maka Ho di tolak dan $\mathrm{Ha}$ diterima, artinya ada perbedaan (ada pengaruh) sebelum dan sesudah adanya perubahan perlakuan

b. nilai signifikansi > 0,05 maka Ho di terima dan Ha ditolak, artinya tidak ada perbedaan (tidak ada pengaruh) sebelum dan sesudah adanya perubahan perlakuan.

\section{HASIL DAN PEMBAHASAN}

\section{Hasil Analisis Data}

\section{Pengujian Instrument}

a. Uji Validitas

Uji validitas terhadap kuesioner penelitian menunjukkan semua indikator adalah valid. Hal ini berarti bahwa indikator dalam kuesioner layak untuk dijadikan 
kuesioner untuk diisi oleh responden. Hasil uji validitas yang telah dilakukan dapat di lihat dalam tabel berikut :

Tabel 1. Validitas Data

\begin{tabular}{cccc}
\hline Indikator & Tingkat signifikan 5\% & $R_{\text {hitung }}$ & Keterangan \\
\hline X1 & $\mathbf{0 , 0 0}$ & $\mathbf{0 , 6 7 2}$ & valid \\
\hline X2 & $\mathbf{0 , 0 0}$ & $\mathbf{0 , 7 1 7}$ & valid \\
\hline Z1 & $\mathbf{0 , 0 0}$ & $\mathbf{0 , 7 0 1}$ & valid \\
\hline Z2 & $\mathbf{0 , 0 0}$ & $\mathbf{0 , 6 9 7}$ & valid \\
\hline & & Uji reliabilitas & terhadap kuesioner
\end{tabular}

Berdasarkan tabel diatas menunjukkan bahwa semua indikator dalam kuesioner memiliki tingkat signifikansi $<0,05$ dan tingkat korelasi >0,4. Dari keterangan tersebut dapat disimpulkan bahwa semua indikator kuesioner adalah valid.

b. Uji Reliabilitas penelitian menunjukkan semua indikator adalah Reliabel. Hal ini berarti bahwa indikator dalam kuesioner layak untuk dijadikan kuesioner untuk diisi oleh responden. Hasil uji reliabilitas data yang telah dilakukan dapat di lihat dalam tabel berikut:

\begin{tabular}{cccc}
\hline \multicolumn{4}{c}{ Tabel 2. Reliabilitas Data } \\
\hline Indikator & $\begin{array}{c}\text { Cronbach's Alpha if } \\
\text { item Deleted }\end{array}$ & $\begin{array}{c}\text { Corrected Item- } \\
\text { Total } \\
\text { Correlation }\end{array}$ & Keterangan \\
X1 & & $\mathbf{0 , 5 4 4}$ & Reliabel \\
$\mathbf{X 2}$ & $\mathbf{0 , 9 1 1}$ & $\mathbf{0 , 4 8 0}$ & Reliabel \\
$\mathbf{Z 1}$ & $\mathbf{0 , 9 1 4}$ & $\mathbf{0 , 5 5 1}$ & Reliabel \\
$\mathbf{Z 2}$ & $\mathbf{0 , 9 1 7}$ & $\mathbf{0 , 5 5 2}$ & Reliabel \\
\hline \\
Hasil Pengujian Hipotesis & & Sample t Test. Analisis ini dilakukan pada \\
Berdasarkan data yang dimiliki & sampel berpasangan. Sampel berpasangan \\
dalam penelitian ini yaitu data rasio yang & yang dimaksudkan adalah subjek penelitian \\
berarti masuk dalam statistik parametrik & yang berbeda. Hasil analisis yang dilakukan \\
maka analisis data yang dilakukan adalah & dengan program SPSS-20 adalah sebagai \\
dengan menggunakan analisis & Paired & berikut:
\end{tabular}

Tabel 3

Berdasarkan tabel.3, uji Paired Sample Statistic menunjukkan bahwa

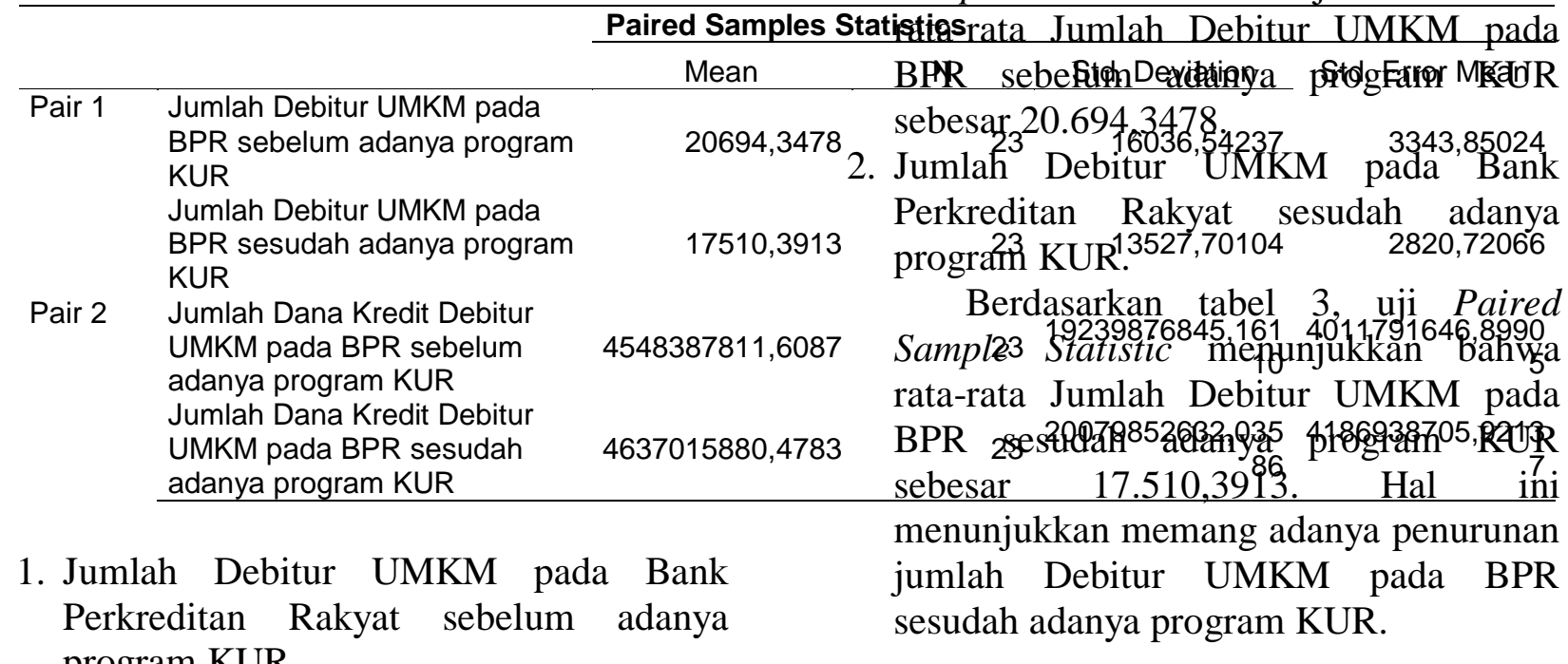
program KUR. 
3. Jumlah Dana Kredit Debitur UMKM pada BPR sebelum adanya program KUR. Berdasarkan tabel 3, uji Paired Sample Statistic menunjukkan bahwa rata-rata Jumlah Dana Kredit Debitur UMKM pada BPR sebelum adanya program KUR sebesar 4.548.387.811, 6087.

4. Jumlah Dana Kredit Debitur UMKM pada BPR sesudah adanya program KUR.

\section{Tabel 4}

Berdasarkan tabel 3, uji Paired Sample Statistic menunjukkan bahwa rata-rata Jumlah Dana Kredit Debitur UMKM pada BPR sesudah adanya program KUR sebesar 4.637.015.880,4783. Hal ini berarti justru ada peningkatan pada Jumlah Dana Kredit Debitur UMKM pada BPR sebelum dan sesudah adanya program KUR.

Paired Samples Test

\begin{tabular}{|c|c|c|c|c|c|c|c|c|c|}
\hline & & \multicolumn{5}{|c|}{ Paired Differences } & \multirow[b]{3}{*}{$t$} & \multirow[b]{3}{*}{ df } & \multirow[t]{3}{*}{$\begin{array}{l}\text { Sig. (2- } \\
\text { tailed) }\end{array}$} \\
\hline & & \multirow[b]{2}{*}{ Mean } & \multirow{2}{*}{$\begin{array}{c}\text { Std. } \\
\text { Deviation }\end{array}$} & \multirow{2}{*}{$\begin{array}{l}\text { Std. Error } \\
\text { Mean }\end{array}$} & \multicolumn{2}{|c|}{$\begin{array}{l}95 \% \text { Confidence } \\
\text { Interval of the } \\
\text { Difference }\end{array}$} & & & \\
\hline & & & & & Lower & Upper & & & \\
\hline Pair 1 & $\begin{array}{l}\text { Jumlah Debitur UMKM } \\
\text { pada BPR sebelum } \\
\text { adanya program KUR - } \\
\text { Jumlah Debitur UMKM } \\
\text { pada BPR sesudah } \\
\text { adanya program KUR }\end{array}$ & 3183,95652 & $\begin{array}{r}11572,13 \\
090\end{array}$ & $\begin{array}{r}2412,956 \\
09\end{array}$ & $\begin{array}{r}- \\
1820,208 \\
13\end{array}$ & $\begin{array}{r}8188,12 \\
118\end{array}$ & $\begin{array}{r}1,3 \\
20\end{array}$ & 22 & ,201 \\
\hline Pair 2 & $\begin{array}{l}\text { Jumlah Dana Kredit } \\
\text { Debitur UMKM pada } \\
\text { BPR sebelum adanya } \\
\text { program KUR - Jumlah } \\
\text { Dana Kredit Debitur } \\
\text { UMKM pada BPR } \\
\text { sesudah adanya } \\
\text { program KUR }\end{array}$ & $\begin{array}{r} \\
- \\
88628068,86 \\
957\end{array}$ & $\begin{array}{r}85231865 \\
9,63397\end{array}$ & $\begin{array}{r}17772072 \\
5,90349\end{array}$ & $\begin{array}{r}- \\
45719829 \\
5,92914\end{array}$ & $\begin{array}{r}2799421 \\
58,1900 \\
1\end{array}$ & $\begin{array}{r}- \\
49\end{array}$ & 22 & ,623 \\
\hline
\end{tabular}

Berdasarkan pada tabel 4, tabel menunjukkan bahwa rata-rata penurunan Jumlah Debitur UMKM pada BPR sebelum dan sesudah adanya program KUR sebesar $3.183,95652$. Sedang rata-rata bertambahnya Jumlah Dana Kredit Debitur UMKM pada BPR sebelum dan sesudah adanya program KUR sebesar 88.628.068,86957. Selanjutnya pada tabel yang sama, yaitu uji Paired Sample $t$ Test menunjukkan bahwa Jumlah Debitur UMKM pada BPR sebelum dan sesudah adanya program KUR sebesar 0,201 yang berarti lebih besar dari $\alpha=0,05$, sehingga keputusan yang diambil adalah menerima Ho. Menerima Ho berarti tidak ada perbedaan yang signifikan mengenai Jumlah Debitur UMKM pada BPR sebelum dan sesudah adanya program KUR. Begitu pula dengan Jumlah Dana Kredit Debitur UMKM pada BPR, berdasarkan uji Paired Sample $t$ Test menunjukkan 0,623 yang berarti lebih besar dari $\alpha=0,05$, sehingga keputusan yang diambil adalah menerima Ho. Menerima Ho berarti tidak ada perbedaan yang signifikan mengenai Jumlah Dana Kredit Debitur UMKM pada BPR sebelum dan sesudah adanya program KUR.

\section{KESIMPULAN}

1. Berdasarkan uji Paired Sample Statistic menunjukkan bahwa rata-rata Jumlah Debitur UMKM pada BPR sebelum adanya program KUR sebesar 20.694,3478. Sedangkan Jumlah Debitur UMKM pada Bank Perkreditan Rakyat sesudah adanya program KUR sebesar 17.510,3913. Hal ini menunjukkan memang adanya penurunan jumlah Debitur UMKM pada BPR sesudah adanya program KUR.

2. Berdasarkan uji Paired Sample Statistic menunjukkan bahwa rata-rata Jumlah 
Dana Kredit Debitur UMKM pada BPR sebelum adanya program KUR sebesar 4.548.387.811, 6087 dan Jumlah Dana Kredit Debitur UMKM pada BPR sesudah adanya program KUR sebesar 4.637.015.880,4783. Hal ini berarti justru ada peningkatan pada Jumlah Dana Kredit Debitur UMKM pada BPR sesudah adanya program KUR

3. Berdasarkan Paired Sample $t$ Test menunjukkan bahwa rata-rata penurunan Jumlah Debitur UMKM pada BPR sebelum dan sesudah adanya program KUR sebesar 3.183,95652. Sedang ratarata bertambahnya Jumlah Dana Kredit Debitur UMKM pada BPR sebelum dan sesudah adanya program KUR sebesar 88.628.068,86957.

4. Berdasarkan uji Paired Sample $t$ Test menunjukkan bahwa Jumlah Debitur UMKM pada BPR sebelum dan sesudah adanya program KUR sebesar 0,201 yang berarti lebih besar dari $\alpha=0,05$, sehingga keputusan yang diambil adalah menerima Ho. Menerima Ho berarti tidak ada perbedaan yang signifikan mengenai Jumlah Debitur UMKM pada BPR sebelum dan sesudah adanya program KUR.

5. Berdasarkan uji Paired Sample $t$ Test menunjukkan Jumlah Dana Kredit Debitur UMKM pada BPR sebelum dan sesudah adanya program KUR sebesar 0,623 yang berarti lebih besar dari $\alpha=$ 0,05 , sehingga keputusan yang diambil adalah menerima Ho. Menerima Ho berarti tidak ada perbedaan yang signifikan mengenai Jumlah Dana Kredit Debitur UMKM pada BPR sebelum dan sesudah adanya program KUR.

\section{DAFTAR PUSTAKA}

Kuncoro, Mudrajad. 2003. Metode Riset Untuk Bisnis \& Ekonomi. Jakarta: Penerbit Erlangga

Singarimbun, Masry \& Sofyan Effendy. 1995. Metodologi Penelitian Survei. Jakarta: LP3ES.

Sugiyono. 2013. Metode Penelitian Kuantitatif Kualitatif Dan $R \& D$. Bandung: Penerbit Alfabeta.

Supranto, J. 2010. Analisis Multivariat Arti \& Interpretasi. Jakarta: PT. RINEKA CIPTA

https://id.wikipedia.org/wiki/Bank_Perkredit an_Rakyat._Diunduh pada tanggal 25 Januari

http://www.lps.go.id/documents/10157/1828 $52 / 1 \mathrm{UU}+\mathrm{No}+7+\mathrm{Th}+1992+\mathrm{ttg}+\mathrm{Perba}$ nkan.pdf

www.ktabank.com.2016/01/bank-penyalurkur-2016.ht 